\title{
An online academic writing and publishing skills course: Help Syrians find their voice
}

\author{
Ammar Sabouni ${ }^{1}$, Abdelkader Chaar ${ }^{2}$, Yamama Bdaiwi $^{3}$, Abdulrahman Masrani ${ }^{4}$, Heba Abolaban $^{5}$, Fares Alahdab ${ }^{6}$, \\ Belal Firwana7, Ahmad Al-Moujahed ${ }^{8}$
}

${ }^{1}$ Medical school, Kasr Al-Ainy Faculty of Medicine, Cairo University, Cairo, Egypt, ${ }^{2}$ Department of Internal Medicine, St John Hospital and Medical Center, Detroit, MI, ${ }^{3}$ Medical school, Faculty of Medicine, Damascus University, Damascus, Syria, ${ }^{4}$ Mallinckrodt Institute of Radiology, Washington University, St Louis, MO, USA, ${ }^{5}$ Department of Public Health, Bouvé College of Health Sciences, Northeastern University, Boston, MA, ${ }^{6}$ Mayo Evidence-based Practice Center, Mayo Clinic, Rochester, MN, ${ }^{7}$ Division of Hematology/Oncology, University of Arkansas for Medical Sciences, Little Rock, AR, USA, ${ }^{8}$ Department of Ophthalmology, Massachusetts Eye and Ear Infirmary, Harvard Medical School, Boston, MA

\begin{tabular}{|c|}
\hline Access this article online \\
\hline Website: www.avicennajmed.com \\
\hline DOI: 10.4103/ajm.AJM_204_16 \\
\hline Quick Response Code: \\
\hline
\end{tabular}

\begin{abstract}
Purpose: A group of Arab-American physicians and researchers in the United States organized a blended online course in academic writing and publishing in medicine targeting medical students and physicians in war-torn Syria. This was an effort to address one of the reasons behind the poor quantity and quality of scientific research papers in Syria and the Arab region. In this paper, we report on the design, conduct, and outcome of this course and attempt to evaluate its effectiveness. Methods: The educational intervention was a 2-month blended online course. We administered a questionnaire to assess satisfaction and self-reported improvement in knowledge, confidence, and skills of academic writing and publishing. Results: The course succeeded in reaching more than 2588 physicians and medical students from the region; 159 of them completed most of the course. Eighty-three percent of the participants felt that they were confident enough to write an academic paper after the course and $95 \%$ felt the learning objectives were achieved with an average student satisfaction of 8.4 out of 10 . Conclusion: Physicians in Syria and neighboring countries are in need of training to become an active part of the global scientific community and to document and communicate the crisis their countries are going through from a medical perspective. Low-cost online educational initiatives help respond, at least partially, to those needs.
\end{abstract}

Key words: Academic writing, Facebook, GoToWebinar, medical education, online course, online learning, social media, YouTube

\section{INTRODUCTION}

Academic writing is an essential component of scientific research, which is invaluable for sustainable health-care development in developing countries. ${ }^{[1,2]}$ English is the language of choice for writing and publishing findings of most scientific research and scientists around the globe aim to publish their research work in English to achieve reach and impact. There are, however, concerns that it is difficult for physicians to get a working command of the academic

Address for correspondence: Dr. Ahmad Al-Moujahed, Department of Ophthalmology, Massachusetts Eye and Ear Infirmary, Harvard Medical School, Boston, MA, USA. E-mail: ahmad_moujahed@meei.harvard.edu writing language, especially those for whom English is a second or third language. ${ }^{[3]}$

The deficiency in academic writing skills is one of the causes behind the shy quantity and poor quality of scientific research papers in the Arab countries. ${ }^{[2,4]}$

This is an open access article distributed under the terms of the Creative Commons Attribution-NonCommercial-ShareAlike 3.0 License, which allows others to remix, tweak, and build upon the work non-commercially, as long as the author is credited and the new creations are licensed under the identical terms.

For reprints contact: reprints@ medknow.com

Cite this article as: Sabouni A, Chaar A, Bdaiwi $\mathrm{Y}$, Masrani A, Abolaban $\mathrm{H}$, Alahdab F, et al. An online academic writing and publishing skills course: Help Syrians find their voice. Avicenna J Med 2017;7:103-9. 
For Syria, a small country suffering unprecedented destruction, the situation is much worse. Although enthusiasm to conduct research may not be lacking among Syrian physicians, ${ }^{[5]}$ it has been trumped by the lack of proper graduate and undergraduate training in academic writing. This has resulted in missed opportunities to communicate knowledge and clinical experience.

It is still not known which practical strategies are the most effective in improving academic writing. ${ }^{[6,7]}$ However, we propose that tackling the lack of proper education and training with the available strategies, including online education, will improve the deficiency in skills of academic writing. In this article, we report on the design, conduct, and participant-reported effectiveness of a course that utilized teleconferencing and social media platforms to teach academic writing and publishing skills.

\section{METHODS}

\section{Study design and participants}

A within-subjects study design with pre- and post-course test and self-reported questionnaires, completed voluntarily by participants, were used. No systematic or validated template was found in the literature to evaluate similar courses. We relied on previous experience from a similar online scientific writing course on which we based a number of our questions with permission from the copyright owners. Through this questionnaire, we aimed to examine the improvement in participants' level of knowledge, skill, and confidence in writing and publishing an academic paper. A consent form was provided at the beginning of each questionnaire/test. This work was exempt from Institutional Review Board (IRB) revision and approval because it was for the sole purpose of evaluation and improvement of an educational initiative. ${ }^{[8]}$ Respondents who agreed to take the pre-course questionnaire, pre-course test, postcourse questionnaire, and post-course test were 385, 296, 106, and 98 attendees, respectively. All questions were optional to answer. Duplicate responses were deleted; when one participant submitted different answers, we kept the most recent. Only those who answered at least 9 out of 13 questions were included in the final analysis.

\section{Online course advertisement and broadcasting}

The online course was advertised on the social network, Facebook $^{\text {twx }}$, through physician, medical student, and general medical groups that were known to have a Syrian majority among their members. Course supervisors, who are a group of Arab-American physicians and researchers, created a Facebook $^{\mathrm{m}}$ group specifically for the participants to facilitate discussions and answer questions. Being a health-care professional that understands the Arabic language was the only condition for accepting course participants. The majority of participants were physicians and medical students (56.6\% and $34.9 \%$, respectively). The interactive platform GoToWebinar (USA) ${ }^{[9]}$ was used to broadcast and record the live sessions. This platform allowed for online webinars with live quiz feedback from the audience. The recordings were later posted on YouTube ${ }^{\mathrm{mm}} \cdot{ }^{[10]}$ This educational intervention lasted over a 2-month period; the weekends of September and October 2015. During this period, participants who attended at least ten sessions out of the 12-lecture course received attendance certificates through E-mail and regular mail, if residing within the United States (US). The titles of the sessions are provided in Appendix 1.

\section{Questionnaire and test assessment}

Participants rated their willingness and confidence in writing academic papers in the medical field using a 7-point Likert scale ranging from 1 (strongly disagree) to 7 (strongly agree) and answered questions with (yes, no) binary options.

Participants were asked several questions regarding their personal satisfaction with the course (e.g., evaluating the effectiveness of each lecture topic, length of lecture, and timing) and were also asked to rate their learning experience on a 3-point Likert scale.

Additional items assessing demographic data, including gender, level of education, location, and job title, were also included in the questionnaire. In addition to both pre- and post-course questionnaires, we included a test of 13 multiple-choice questions to estimate the participants' competency in writing a scientific paper. We compared preand post-course questionnaires and tests to assess the impact of attending this course. Appendix 2 contains the test questions.

\section{Data analysis}

All data were entered into a Microsoft Excel spreadsheet and exported for analysis using the statistical software Statistical Package for the Social Sciences (SPSS, version 21.0) (SPSS Inc. SPSS statistics for Windows. Ver. 21.0. Armonk, NY: IBM; 2012) ${ }^{[11]}$ Pearson Chi-square test was used for comparing categorical variables. $P<0.05$ was taken to denote statistical significance.

Frequencies and descriptive summaries for categorical data were used to summarize questionnaire answers data.

\section{RESULTS}

\section{Participants}

A total of 2588 health-care professionals joined the 
Facebook $^{\text {mm }}$ group and 385 participants completed the pre-course questionnaire. Participants who attended two sessions or more were 242 and those who attended at least ten sessions (i.e., became eligible to receive a certificate of attendance) were 159. Out of these 159 participants, 106 completed the post-course questionnaire and test (64 males, 31 females, and 11 did not report gender). Fifty-five percent (55\%) attended the course from Syria, 20\% from the Arabian Gulf area, 2.9\% from Egypt, 1.9\% from Jordan, 1\% from Lebanon, and $1 \%$ from Sudan. Participants from the US and Europe made up $18.1 \%$, (9.5\% and $8.6 \%$, respectively) of all participants [Table 1].

\section{Reasons for joining the course}

When asked about the reasons for joining the course, 97\% of the participants had a general interest in the topic, $92 \%$ wanted to learn a new skill to improve their career, $84 \%$ were interested in getting a certificate, whereas $80 \%$ joined the course to improve their language skills. Other reasons included the desire to experience an online course for the first time or just to challenge themselves.

\section{Perception of confidence and skills in writing}

Before the course, $55 \%$ of enrolled students felt they were confident enough to produce a research paper. This percentage increased to $83 \%$ after completion of the course [Figure 1]. Ninety-five percent of the attendees felt they had reached their learning objectives after the course and the average satisfaction rate was 8.14 out of 10 . Seventy-four percent of the participants preferred the live over the recorded lectures and $56.7 \%$ supported that the language of teaching was Arabic. All of the respondents to the post-course questionnaire showed interest in writing a scientific paper; half of them already had an idea to write about [Table 2].

\section{Course test}

We compared responses to the 13 questions in the pre- and post-course tests to measure the change in academic writing skills. Participants improved significantly in $30 \%$ and had no

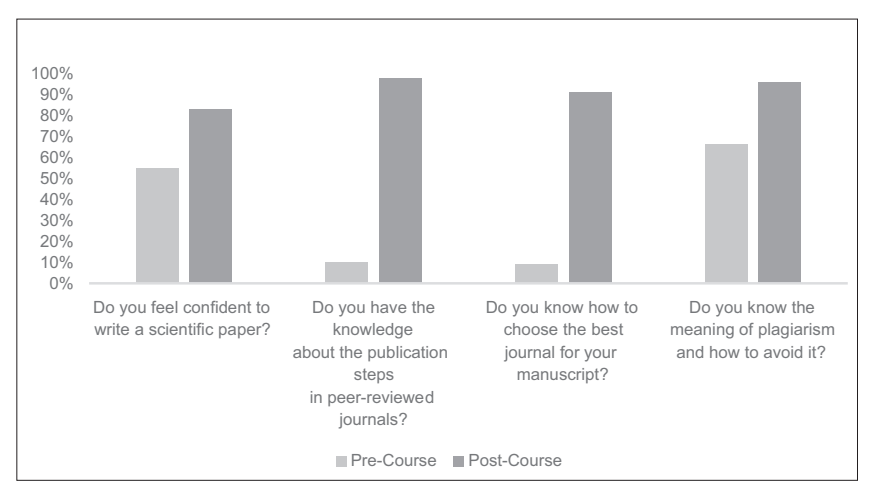

Figure 1: Self-assessment comparison of the level of knowledge about core topics of academic writing before $(n=385)$ and after $(n=106)$ the course significant change in $62 \%$ of the questions. They showed a significant decline in one of the 13 questions [Table 3]. The questions are mentioned in Appendix 2.

\begin{tabular}{|c|c|}
\hline \multicolumn{2}{|c|}{$\begin{array}{l}\text { Table I: Characteristics of course participants who } \\
\text { completed the pre-course survey }\end{array}$} \\
\hline & $n(\%)$ \\
\hline \multicolumn{2}{|l|}{ Gender } \\
\hline Male & $64(67.4)$ \\
\hline Female & $31(32.6)$ \\
\hline \multicolumn{2}{|l|}{ Current location } \\
\hline Syria & $58(55.2)$ \\
\hline Gulf & $21(20)$ \\
\hline USA & $10(9.5)$ \\
\hline Europe & $9(8.6)$ \\
\hline Egypt & $3(2.9)$ \\
\hline Jordan & $2(1.9)$ \\
\hline Lebanon & I (I) \\
\hline Sudan & I (I) \\
\hline \multicolumn{2}{|l|}{ Education } \\
\hline Medical student & $37(36)$ \\
\hline Graduate/general medicine & $23(22.3)$ \\
\hline Postgraduate/specialized & $35(34)$ \\
\hline $\mathrm{PhD}$ & $5(4.9)$ \\
\hline Pharmacy & $2(1.9)$ \\
\hline Others & $1(1)$ \\
\hline
\end{tabular}

\begin{tabular}{lc}
\hline Table 2: Post-course survey responses & \\
\hline & $\mathbf{n}(\%)$ \\
\hline $\begin{array}{l}\text { Lectures length was } \\
\text { Good }\end{array}$ & $65(61.3)$ \\
Long & $41(38.7)$ \\
Lectures timing was suitable & $90(90.6)$ \\
Preferred type of lectures & \\
$\quad$ Live & $77(74)$ \\
$\quad$ Recorded & $27(26)$ \\
Preferred language of lectures & \\
$\quad$ English & $45(43.3)$ \\
Arabic & $59(56.7)$ \\
I intend to teach what I learned in this course to my peers & $77(73.3)$ \\
I participated in an academic writing-related activity before & $38(36.2)$ \\
I will seriously consider working on a manuscript to \\
publish in a peer-reviewed journal \\
I fulfilled my educational goal from this course \\
\hline
\end{tabular}

\begin{tabular}{|c|c|c|c|c|}
\hline $\begin{array}{l}\text { Question } \\
\text { number }\end{array}$ & $\begin{array}{l}\text { Pre-course } \\
\text { (\%) }\end{array}$ & $\begin{array}{l}\text { Post-course } \\
\text { (\%) }\end{array}$ & $\begin{array}{l}\text { Difference } \\
\text { (\%) }\end{array}$ & $P$ value \\
\hline QI & $56.5 I$ & 46.88 & -9.63 & 0.100 \\
\hline Q2 & 42.23 & 56.12 & 13.89 & 0.017 \\
\hline Q3 & 97.97 & 95.92 & -2.05 & 0.262 \\
\hline Q4 & 88.18 & 87.76 & -0.42 & 0.911 \\
\hline Q5 & 92.20 & 87.76 & -4.45 & 0.180 \\
\hline Q6 & 57.68 & 77.55 & 19.87 & $<0.001$ \\
\hline Q7 & 56.66 & 68.37 & II.7| & 0.041 \\
\hline Q8 & 71.08 & 70.89 & -0.19 & 0.974 \\
\hline Q9 & 64.90 & 48.72 & -16.19 & 0.013 \\
\hline Q10 & 22.11 & 58.76 & 36.66 & $<0.001$ \\
\hline QII & 46.15 & 41.67 & -4.49 & 0.444 \\
\hline Q12 & 44.25 & 59.38 & 15.12 & 0.10 \\
\hline Q13 & 93.20 & 87.63 & -5.57 & 0.83 \\
\hline
\end{tabular}




\section{DISCUSSION}

Since medical students and physicians may struggle in writing scientific papers if they do not receive proper education in academic writing, ${ }^{[12]}$ effective educational courses and activities that address this topic are needed. Multiple studies have been conducted to evaluate different styles of courses that are designed to improve the skills of academic writing and publishing in English. ${ }^{[6,7,13]}$ Since a large proportion of research papers originating from the Middle East and Africa contain significant English language flaws, ${ }^{[3,14]}$ which reflects negatively on the chances of getting published, it is important to design and evaluate such a course that is directed to the Arab countries. According to our knowledge, our study is the first of its type in this region.

Although live writer retreats and support groups have been shown to increase productivity in academic publishing, ${ }^{[6,15,16]}$ a live face-to-face course was difficult to achieve in our circumstances, especially in Syria. We found that our low-cost blended online approach (i.e., synchronous sessions via GoToWebinar in addition to posting the recorded sessions on YouTube ${ }^{\mathrm{Tw}}$ along with posting educational materials and facilitating discussions on Facebook ${ }^{\mathrm{Tm}}$ ) was able to reach a large number of early career researchers and students in the Arab region, more than half of them were from Syria. It also satisfied what they perceived as their needs in the field of academic writing and publishing. While the majority of students preferred the live online lectures to the video recordings, availability of the recordings was very beneficial for students who had limited continuous access to internet connection or electricity.

Since Arabic is the language of medical education in Syria ${ }^{[4]}$ and the first spoken language in the countries targeted by our educational intervention, using Arabic for teaching and interaction with students during the course was welcomed by more than half of the participants.

Objective evaluation of our intervention was challenging, especially that real outcomes would be quality and number of scientific publications in the targeted region. Although planning real writing assignments with grading would have been a better approach, available human resources came in the way of implementing such a strategy. Instead, we prepared a number of knowledge-based and example-led questions. Although students were satisfied with the course, the majority of the knowledge-based questions did not show improvement. The questions that did show improvement had a common characteristic of being related to the practical application of academic writing. This may indicate that our intervention improved students' ability to write academic papers, which could also be concluded from the observed increase in participants' confidence about writing a scientific paper after the course $(55 \%$ vs. $83 \%$ before and after the course, respectively).

It is estimated that $82 \%$ of internet users in the Arab region use Facebook ${ }^{\mathrm{rm}}$. ${ }^{[17]}$ Therefore, we used a hybrid method that utilizes a teleconference platform in addition to social media, which found to be a simple and popular recruiting platform. Our Facebook ${ }^{\mathrm{mm}}$ group also served as a type of peer support group between speakers and participants to encourage a positive learning environment. Our online teaching method had similar limitations to Massive Online Open Courses (MOOCs) in that although medical students in nearby Egypt were found to use and benefit from MOOCs, a large number did not complete them. ${ }^{[18]}$ Using improved platforms and stronger methods for evaluating the course outcomes over a long period of time (e.g., the number of peer-reviewed publications) could further enhance the benefits and effectiveness of online education in improving academic writing and publishing skills in the Arab region, similar to eLearning modules that have been shown to be effective in other parts of the world. ${ }^{[15,19]}$ Since academic writing and publishing are essential skills to participate in academia and become part of the global scientific community, ${ }^{[20]}$ courses that improve these skills may be an important factor in enhancing the quantity and quality of clinicians who pursue academic careers in the Arab region, especially that there has been a steady decline in the number of clinicians in academia worldwide. ${ }^{[21]}$

\section{Limitations of the study}

One of the limitations of our study was that we had a heterogeneous audience consisting of health-care professionals at different levels of their careers, with different educational and literacy backgrounds, and from different countries. Therefore, participants starting at a more advanced level could have perceived a smaller improvement. Students may have also overestimated their competencies before or after the course. Therefore, using self-confidence of the participants could also be a limitation in evaluating the effectiveness of this course.

Another limitation is that the evaluation method was not completely objective. Designing a comprehensive questionnaire to evaluate our course was challenging and, according to our knowledge and literature search, there is no validated questionnaire to evaluate similar courses. In addition, we could not match the answers of the pre- and post-course questionnaire and test for the same participant to measure the improvement individually because we did not have any unique identifiers. 
We believe that our evaluation was not able to reflect the true benefit our course participants gained.

\section{CONCLUSION}

In an effort to mitigate the weakness in academic writing and publishing in Syria and the Arab World, a low-cost online course using a hybrid teleconferencing and social media platform proved efficient in reaching a wide audience in a difficult to reach region with satisfying their perceived needs. More efforts need to be made to improve medical academic writing in the region and to effectively evaluate improvement. We recommend implementing further courses of this type with considering the current limitations into account.

\section{Acknowledgments}

The authors acknowledge the help of the Education Committee at the Syrian American Medical Society that provided logistic and technical support. We also acknowledge the help of Prof. Sainani from SciWrite Stanford whose questionnaire we relied on in writing our questions.

\section{Financial support and sponsorship}

Nil.

\section{Conflicts of interest}

There are no conflicts of interest.

\section{REFERENCES}

1. Nuyens Y. Setting priorities for health research: Lessons from low-and middle-income countries. Bull World Health Organ 2007;85:319-21.

2. Young BK, Cai F, Tandon VJ, George P, Greenberg PB. Promoting medical student research productivity: The student perspective. R I Med J 2014;97:50-2.

3. Gholami J, Zeinolabedini M. A diagnostic analysis of erroneous language in iranian medical specialists' research papers. J Tehran Heart Cent 2015;10:58-67.

4. Diab MM, Taftaf RM, Arabi M. Research productivity in Syria: Quantitative and qualitative analysis of current status. Avicenna J Med 2011;1:4-7.
5. Alahdab F, Firwana B, Hasan R, Sonbol MB, Fares M, Alnahhas I, et al. Undergraduate medical students' perceptions, attitudes, and competencies in evidence-based medicine (EBM), and their understanding of EBM reality in Syria. BMC Res Notes 2012;5:431.

6. Rickard CM, McGrail MR, Jones R, O'Meara P, Robinson A, Burley M, et al. Supporting academic publication: Evaluation of a writing course combined with writers' support group. Nurse Educ Today 2009;29:516-21.

7. Oermann MH, Leonardelli AK, Turner KM, Hawks SJ, Derouin AL, Hueckel RM. Systematic review of educational programs and strategies for developing students' and nurses' writing skills. J Nurs Educ 2015;54:28-34.

8. Code of federal regulations. Final rules. Fed Regist. 2006 Mar 45;46.101(b).

9. GoToWebinar. Available from: https://www.gotomeeting.com/en-gb/ webinar. [Last accessed on $2017 \mathrm{Apr}$ 08].

10. YouTube. SAMS Academic Writing in Medicine Online Course; 2015. Available from: https://www.youtube.com/playlist?list=PLr1yaLM_ bf04uTVcG5sJvcF0XKBFunT0r. [Last accessed on 2017 Apr 08].

11. IBM. SPSS statistics for Windows. Version 21.0. Armonk, NY: IBM; 2012.

12. Rawson RE, Quinlan KM, Cooper BJ, Fewtrell C, Matlow JR. Writing-skills development in the health professions. Teach Learn Med 2005;17:233-8.

13. Salamonson Y, Koch J, Weaver R, Everett B, Jackson D. Embedded academic writing support for nursing students with English as a second language. J Adv Nurs 2010;66:413-21.

14. Kaliyadan F, Thalamkandathil N, Parupalli SR, Amin TT, Balaha MH, Al Bu Ali WH. English language proficiency and academic performance: A study of a medical preparatory year program in Saudi Arabia. Avicenna J Med 2015;5:140-4.

15. Brandon C, Jamadar D, Girish G, Dong Q, Morag Y, Mullan P. Peer support of a faculty "writers' circle" increases confidence and productivity in generating scholarship. Acad Radiol 2015;22:534-8.

16. Cable CT, Boyer D, Colbert CY, Boyer EW. The writing retreat: A high-yield clinical faculty development opportunity in academic writing. J Grad Med Educ 2013;5:299-302.

17. Dennis EE, Martin JD, Wood R. Media use in the Middle East, 2016: A Six-Nation Survey; 2016. Available from: http://www.mideastmedia. org/survey/2016. [Last accessed 2017 Apr 18].

18. Aboshady OA, Radwan AE, Eltaweel AR, Azzam A, Aboelnaga AA, Hashem HA, et al. Perception and use of massive open online courses among medical students in a developing country: Multicentre cross-sectional study. BMJ Open 2015;5:e006804.

19. Pintz C, Posey L. Preparing students for graduate study: An eLearning approach. Nurse Educ Today 2013;33:734-8.

20. Borglin G. Promoting critical thinking and academic writing skills in nurse education. Nurse Educ Today 2012;32:611-3.

21. Fitzpatrick S. A Survey of Staffing Levels of Medical Clinical Academics in UK Medical Schools as at 31 July, 2011. Medical Schools Council; 2012. 


\section{APPENDIX}

\section{Appendix 1: Session titles}

1. Introduction and overview

2. Principles of Effective Writing 1

3. Principles of Effective Writing 2

4. Structure of a Scientific Paper

5. Writing a case report

6. Writing a Literature Review

7. Writing a Scientific Abstract

8. Research and Publishing During Disaster Time

9. Using a Reference Manager

10. The Publication Process

11. Issues in Scientific Writing

12. Publication from an Editor's Perspective.

\section{Appendix 2: Test questions}

1. What is the main problem of this sentence: "The initial symptoms of Alzheimer's disease are difficulties learning new material and in memory for recent events."

- A run-on sentence

- Lacks parallel structure

- In the passive voice

- Contains unnecessary adverbs.

2. Choose the best verb tense to be used in a scientific manuscript

- The drug group has a higher incidence of fractures than the placebo group

- The drug group had a higher incidence of fractures than the placebo group

- The drug group was having a higher incidence of fractures than the placebo group

- The drug group has had a higher incidence of fractures than the placebo group.

3. Choose the sentence that contains a passive voice:

- Figure 2 shows the increase in inflammation in the control group

- The end of the recession is almost here

- He challenged their theory about subatomic particles

- Their weights were measured using a balance beam scale.

4. Choose the sentence that contains active voice

- The experiment was set up too quickly

- The data are shown in Table 2

- The researchers presented an interesting theory

- Their results were interpreted unfairly.

5. The introduction of a scientific manuscript should be:

- Broad description of all the research that has been done on the topic

- Stating the objective, hypothesis, or the medical question of the study

- Not less than 6 paragraphs

- No more than ten paragraphs.

6. While reading paper A, you read this sentence: " $20 \%$ of adult population has condition X, reference paper B"; if you want to reuse this sentence, you should:

- $\quad$ Cite paper A 
- $\quad$ Cite paper B

- You look for the original source of the statistic and cite it

- Avoid mentioning the statistics because it is considered plagiarism.

7. In the manuscript, the discussion section should start with:

- Mentioning the main weakness points and limitations of the study

- $\quad$ Review the strength points of the study

- Clearly stating the main results of the study

- $\quad$ Stating the research hypothesis for the first time.

8. You should reply to the reviewers as follows:

- You can ignore the comments that you do not like

- You should make every change as requested by the reviewer

- You should reply to every comment even if you do not make the requested change

- You should put in long time and big effort to criticize the comments of the reviewers.

9. What is single blinded peer-review?

- Authors do not know the reviewers

- Editors do not know the authors

- Reviewers do not know the authors

- $\quad$ Readers do not know the authors.

10. How to improve this sentence: "The dysmorphic malignant cells showed profuse proliferation throughout the organ, whereas infected individuals showed poor growth and often died."?

- Bring the subject and main verb of the sentence closer together

- Change the nouns "proliferation" and "growth" into verbs

- Eliminate the adverb "often"

- Break the sentence into two shorter sentences

11. Mention one problem of this sentence: "These indexes are promising because of their simplicity, their potential applicability to different tissue types, and by not requiring complex measuring devices and large cost investments for its evaluation."

- Lacks parallel structure

- Contains too much technical jargon

- Is incomplete

- In the passive voice.

12. The following description appeared in a copyrighted publication about ECG machines: The ten electrodes attached to the patient's limbs and chest, serve as sensors for electrical potential, recording the overall magnitude and direction of the heart's electrical depolarization. Later, a student wrote in his/her essay about the research: They attached ten electrodes (round $24 \mathrm{~mm}$, polymer $\mathrm{Ag} / \mathrm{AgCl}$ coated) to the patient's limbs and chest to serve as sensors for electrical potential, recording the overall magnitude and direction of the heart's electrical depolarization.

Is that considered a plagiarism?

- Maybe, it is alone not plagiarism. But it is expected that the student copied from the text more than what is mentioned

- No, because the student has changed the sentence structure

- Yes, because the student copied the test without putting quotation marks

- No, plagiarism is copying complete sentence or 20 words, this manuscript does not qualify for plagiarism.

13. When it comes to the authorship, the researchers should:

- Give author title to anyone who participated in the research

- Give author title only to who holds a PhD degree

- Give author title to who did all the following: study design, data gathering, data analysis, manuscript writing and editing. 